\title{
Measuring physical changes in an urban regeneration scheme
}

\author{
S. Y. Said, S. S. Syed Zubir \& M. N. Rahmat \\ Faculty of Architecture, Planning and Surveying, \\ Universiti Teknologi MARA, Malaysia
}

\begin{abstract}
Urban regeneration refers to the process of improving the condition of urban quarters, mostly the dilapidated historic areas. The heritage-led urban regeneration induces life into decaying assets and developing the future potential of a neighbourhood. It is a comprehensive and integrated vision and action which leads to the resolution of urban problems and which seeks to bring a lasting improvement into the economic, physical, social and environment condition of an area that has been subject to change. The changes in physical aspect of urban areas represent the impact of the regeneration scheme on the place. Improve condition of historic areas resulting from the conservation work carried out is believed to support the regeneration of the area as a whole. A detailed analysis of the historical context of the built form could provide valuable information of the urban morphology of the place. Townscape evaluation is a quantitative data collection methodology used to assess the physical condition of the urban heritage areas. This method involves a scoring system and has been used to assess the effectiveness of Townscape Heritage Initiatives schemes in the UK. Improvements in socio-cultural indicators in the score sheet have been made and used in the assessment of historic urban characteristics of heritage areas in Malaysia. The result from the assessment serves as a baseline indicators for the condition of the townscape of the heritage areas. The results highlighted the areas that require further improvement, hence to support future regeneration initiatives.
\end{abstract}

Keywords: regeneration, sustainable, townscape assessment, baseline indicator. 


\section{Introduction}

The conservation scheme involves upgrading and re-branding initiatives for historic buildings to cater for modern usage in an economic inducement plan for the historic cities, the end results will lead to economic regeneration of the area. Many places has benefitted from urban regeneration scheme, since it was introduced in late 1990s as new way of saving historic areas and places from decline. Capital invested towards heritage asset and areas helped to provide a better living condition and attracted people to come and live in the conserved areas. Besides, economic inducement provides a boost towards local economy, thus create more job opportunities for the residents.

Urban conservation in the form of heritage-led regeneration introduces changes in the townscape directly and indirectly. These changes are part of the process of the formation and transformation of the place. The study on urban morphology is important to record the changes in order to establish level of transformation throughout time. It marks the level of success of the schemes. Townscape evaluation, a quantitative data collection methodology used to assess the physical condition of the urban heritage areas. The similar practice was carried out to assess the effectiveness of Townscape Heritage Initiatives scheme in the UK supported by Heritage Lottery Fund. The townscape evaluation was carried out every five years to monitor the physical changes and the effect of the regeneration scheme to physical, economy and social of the area based on observation and its quantitative performance based on the score gained.

\section{Assessing the townscape}

Townscape assessment methodology has been developed further by a group of researchers at Oxford Brookes University led by Dr. Alan Reeve. The method was initially developed by Professor Brian Goodey for the London Borough of Tower Hamlets Trust in 1978. It has been refined for a number of large scale projects such as the 1999 London Transport Survey of the Jubilee Line Extension to London's Underground [1]. This approach was adopted to evaluate the effectiveness of their funding of regeneration projects. The assessment is a longitudinal research study which started in 1998 (continuing) and followed by five yearly reviews. The correlation between the study of buildings, form, fabric and function, their environment and setting and the relationship with the occupants provides a dynamic example for this type of research.

Reeve explains that in order to develop the most suitable methods for the assessment of Townscape Heritage Initiatives (THI) projects, research on a townscape analysis technique was taken into account 'to provide some recommendations for its applications in both urban design and urban morphology' [2].

The research had adapted the components of the methodology used in the THI such as questionnaires, interviews, townscape surveys and secondary data, in both the pilot study and the fieldwork carried out. The adaptation considered the 
importance of culture and religious aspects of the community, which provide the roots of stability. It is a unique characteristic of the multi-ethnic country to be assessed. Furthermore, these criteria were in accordance with Criterion (ii) of the Outstanding Universal Value for the World Heritage Sites, in which both the case study areas for this research; Melaka and George Town were recognised in the List [3].

Studies by Solomon and Johnston in the late 1960s emphasise the importance of townscape analysis in order to study the relationship of buildings and their occupants [4]. Solomon explains that to understand the character of a townscape, a detailed analysis of the buildings and their historical context could provide guidelines for the townscape characteristics. A similar approach was carried out by Reeve in conducting the townscape survey method for the THI assessment.

The assessment of these criteria was made through observation, structured interviews with the residents and property managers. Nevertheless, cultural and religious values are subjective and difficult to quantify. However, fractal analysis extended by Cooper to include Taiwanese evidence suggests that culture has a deep-seated influence on the formation of a townscape attitude [5]. The study on the layout of historic cities in Malaysia reflects the importance of religious and cultural aspect in the society. This supports the need to assess these values in order to learn how the regeneration will affect diverse, multi-ethnic society such as Malaysia.

The townscape assessment involves a scoring system whereby a minimum and maximum score system is used [6]. The score is then aggregated and the result forms the percentage of success or failure of the area under different criteria. These criteria are under the headings of streetscape: quality and maintenance, private space in view and heritage in view. The criteria cover social and environmental qualities of the area in terms of planning and the townscape quality of the area, as well as the conservation and maintenance of the buildings. Apart from the score sheet, data are supported by photographic evidence.

\section{The indicators}

Since the early 1990s, the use of indicators to evaluate changes in social studies has become a worldwide phenomenon [7]. The value of indicators as a form of knowledge is based on their methodological process from abstract concepts to specific and concrete measures to yield policy intelligence. The concept of tracking changes in specific indicators has been continually developed over the last generation in order to evaluate the effects of interventions [6]. To allow a thorough evaluation, a sub-set of conditions had been identified, based on the characteristics that underlined in the framework of the research.

The formation of the four key indicators were based on the deduction and cross referencing done between the characteristics/ indicators used for the pilot study, the result from the analysis of the structured interviews and the indicators used in the assessment of heritage-led regeneration schemes through THI assessments and 
European Association of Historic Town and Region (EAHTR) [8]. The four characteristics or key indicators used for the study were:

- Social and cultural indicator

- Townscape improvement indicator

- Economic regeneration indicator

- Image and identity indicator

Each of the indicators was supported by various information and data streams used to form analysis of the field study and to act as a main framework which formed the conclusion of the study. The theme was supported with sub-indicators that were designed to provide a thorough and competent assessment, unique for Malaysia, as it considered all the underlying aspects of tangible and intangible heritage that are considered important.

Nevertheless, to measure the physical changes of the historic areas, only two indicators are suitable; the Townscape improvement indicator and Image and identity indicator. The other two indicators are based on the data gathered through interview sessions, questionnaire survey and from local government reports.

\subsection{Physical and environmental indicators}

This indicator was used to assess the townscape quality, building conditions, traffic management system, heritage preservation activities and the condition of the public realm and tourism facilities.

\subsubsection{Building and environment}

The building conditions refer to the physical condition of the structure, building use and conservation work carried out. Measures of this aspect were derived from the townscape survey work, combined with comments from the interviewees and responses from the questionnaire surveys.

\subsubsection{Traffic Management System}

This refers to the traffic system circulation to, and from, the survey area. It also refers to the level and quality of activity in a given area, by a variety of users, and the level of use. The measures are of the traffic flow and travel time within the area and are derived from the results of the townscape assessment and the study of the Draft Conservation Management Plan.

\subsubsection{Infrastructure and public realm}

The quality of infrastructure and the public realm is assessed by the way the physical environment is maintained and cared for. This includes the use of signage, the fitting of street furniture, the accessibility guide, the drainage system, street lighting and the quality of the road surfaces and pedestrian walkways. The quality of the environment includes the level of cleanliness and facilities provided; i.e. the location and the suitable number of wheelie bins provided. Changes in this realm were captured through townscape assessment and streetscape observation. 


\subsubsection{Tourism facilities}

The accessibility, maintenance and quality of tourism facilities were assessed through the questionnaire survey, interviews and observation made during the field study.

\subsection{Image and identity indicators}

The indicator for image and identity refers to the heritage resource and interpretation in the study area. The heritage resource was assessed by the façade quality, structural condition, maintenance work and the way the heritage was presented.

\subsubsection{Heritage resource}

The condition and type of heritage resource were measured to provide a general idea of the type of heritage resources in the area, to provide an opportunity to market and promote the resource. The observations during the field study formed a part of the assessment of this indicator, but the questionnaire survey, interviews, press coverage and records from the Department of Heritage were consulted to determine the value.

\subsubsection{Façade quality}

The quality of façades is the main attraction for visitors to historic cities. Physical quality and special characteristics, i.e. ornamentations, contribute to the measurement for this indicator. Besides that, structural conditions and maintenance work were assessed to determine not only the quality of the historical restoration but the perception that such work leaves. The measurements were collected through questionnaire surveys, townscape survey, observations and structured interviews.

\subsubsection{Tourism and sustainability}

The attraction of the historic areas to visitors and the possibility of the area being able to maintain and continue improvements are related to the attractiveness of the townscape to continue to attract tourists for a long period. The assessments are based on data from interviews, questionnaires and data from Tourism Malaysia.

\section{The assessment}

The assessment carried out in the current research involved observation of the townscape, mapping, scoring and photographic evidence. Twenty variables were selected for the pilot study and twenty five were eventually produced for the field work (Table 1). The variables were analysed according to the themes, which for this survey, were derived from a combination of the THI evaluation form, the Investing in Heritage to Regenerate Historic Cities (INHERIT) indicators by EAHTR and from information collected through the literature review.

The scoring system is based on a Likert style scale, where it uses a five point system. In this system, the scores range from 'strongly agree' to 'strongly disagree', with the value of 5 to 1 . The respondents indicate degree of agreement 
using categories such as 'strongly agree', 'agree', 'undecided', 'disagree' and 'strongly disagree' [9-11]. For the present research, a dichotomous combination based on the themes designed for the survey was used. For example, 'totally tolerable' to 'totally intolerable' for a social characteristic, or 'excellent' to 'worst' for building and conservation.

Table 1: Variables used to assess the townscape quality.

\begin{tabular}{|l|l|}
\hline Part A: Environmental Quality and & Part B: Heritage Appreciation (in view) \\
\hline Streetscape & \\
\hline 1. Street scene & 16. Heritage resource \\
3. Traffe of the building & 17. Façade Quality \\
4. Accessibility (point to point) & 18. Building usage \\
5. Personal safety: traffic & 19. Building/Structural Condition \\
6. Street furniture quality & 20. Quality of Conservation work \\
7. Road/ Pedestrian walkway condition & 21. Appropriateness of work (sense of \\
8. Infrastructure (water/electricity/refuse) & space) \\
9. Signage (building) & Part C: Special Characteristic and Identity \\
10. Legibility & \\
11. Drainage and sewer system & 22. Evidence of historic significance \\
12. Street lighting & 23. Quality of new development \\
13. Cleanliness & 24. Conserved element evidence \\
14. Coherence & 25. Harmony between old and new \\
15. Vitality & \\
\hline
\end{tabular}

Table 2: Townscape survey score used in the pilot study.

\begin{tabular}{|c|l|l|l|}
\hline The score & $\begin{array}{l}\text { Physical } \\
\text { characteristic }\end{array}$ & Social & $\begin{array}{l}\text { Building and } \\
\text { Conservation }\end{array}$ \\
\hline 0 & Absent & & \\
\hline 1 & Worst & Totally intolerable & Worst \\
\hline 2 & Bad & Intolerable & Bad \\
\hline 3 & Fair & Undecided & Undecided \\
\hline 4 & Good & Tolerable & Good \\
\hline 5 & Excellent & Totally tolerable & Excellent \\
\hline
\end{tabular}

For physical characteristics, a 6 point scale system is used with the additional scoring of 0 (zero) for 'absent' (Table 2). The 6 point system was also used in the THI evaluation, although not all scores would be available for all variables [6]. For the pilot research the scoring was from zero to five. In which zero represents the lowest score for absence of surveyed criteria, and five represents the highest score for excellence condition of the assessed criteria. The total score was 100. As for the townscape assessment for the case study areas, the similar scoring system were used; however, there are changes and addition in assessed criteria which the total score was 125 .

Table 3 gives an example of the interpretation of the scoring. 
Table 3: Example of the interpretation of the scoring.

17. Façade Quality: An assessment of façades (in view) of the buildings reflecting on overall quality of design, maintenance and immediate presentation.

High: Well-maintained façade, concerned presentation to the street.

Low: Poorly maintained and managed façade reflecting little concern for the street setting.

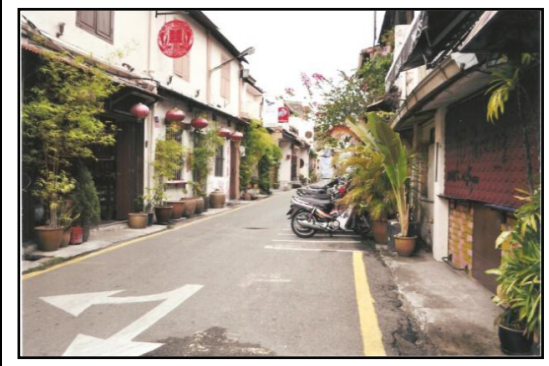

Façade quality score: 5

Location: Kasturi Street, Melaka

This area scored 5 (high) because it shows the evidence of the good condition of the façade. The buildings are well-maintained with high quality conservation work reflecting the image of the location. This contributed to the score.

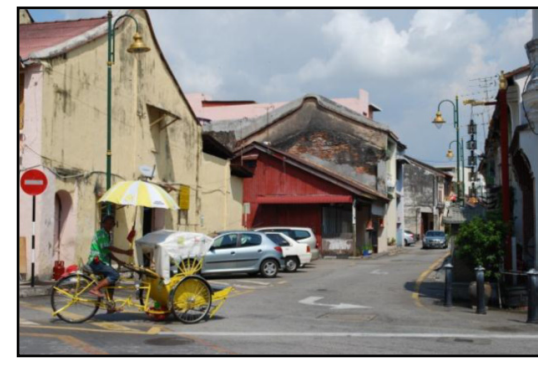

Façade quality score: 1

Location: Lebuh Ah Quee, George Town

This area scored 1 (low) because of the poor condition of the façades. The mouldy walls created disturbing views of the area, hence the low score.

\section{The result}

The quantitative value from the assessment would provide an ideal data to monitor changes taking place in the surveyed area which is essential for base line research. The numerical result was represented in an iso-line representation on a map, and plotted according to criteria to show the performance of the area. This allows the researcher to highlight graphically where change has occurred, and to provide a graphical representation of numerical scores of a base line study, that could be compared with the score plotted in the next review - carried out from the same viewpoint as the base line study, where the photographic evidence taken during the study plays an important role to determine the exact location, where assessments were carried out [12].

The scoring helps to summarize a detail visual description of the assessed area. The result from the surveys suggests major changes have taken place within the three years since the first survey was carried out (Figures 1 and 2). The lowest iso-line representing 50 score (lightest rendering) as the lowest score in 2013 show a decline in score compared to 60 score recorded for 2010 . However, overall scores indicate that the quality of the townscape increases is high, where more than $50 \%$ of the heritage core zone area of Melaka scored above 80. The peak of the iso-lines which represent the scores 90 to 100 covers a wider area. 


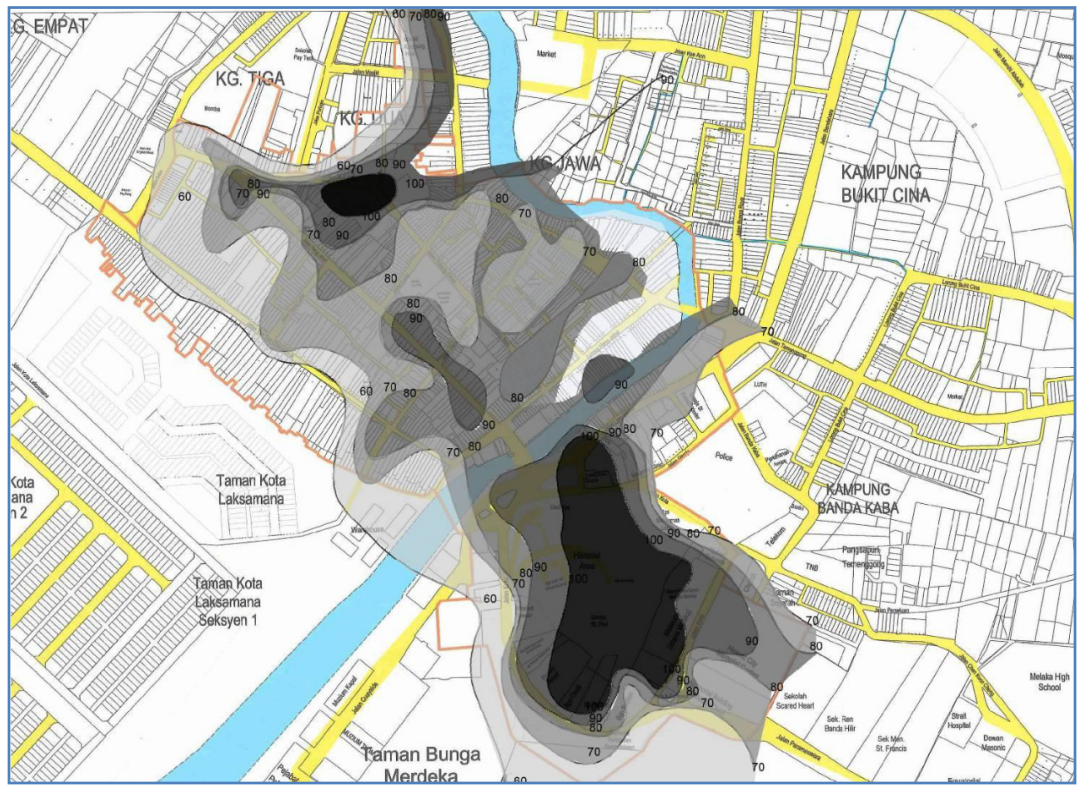

Figure 1: Iso-lines map representing the quality of townscape assessed in 2010. Darker rendering indicates the higher level of scores (townscape quality).

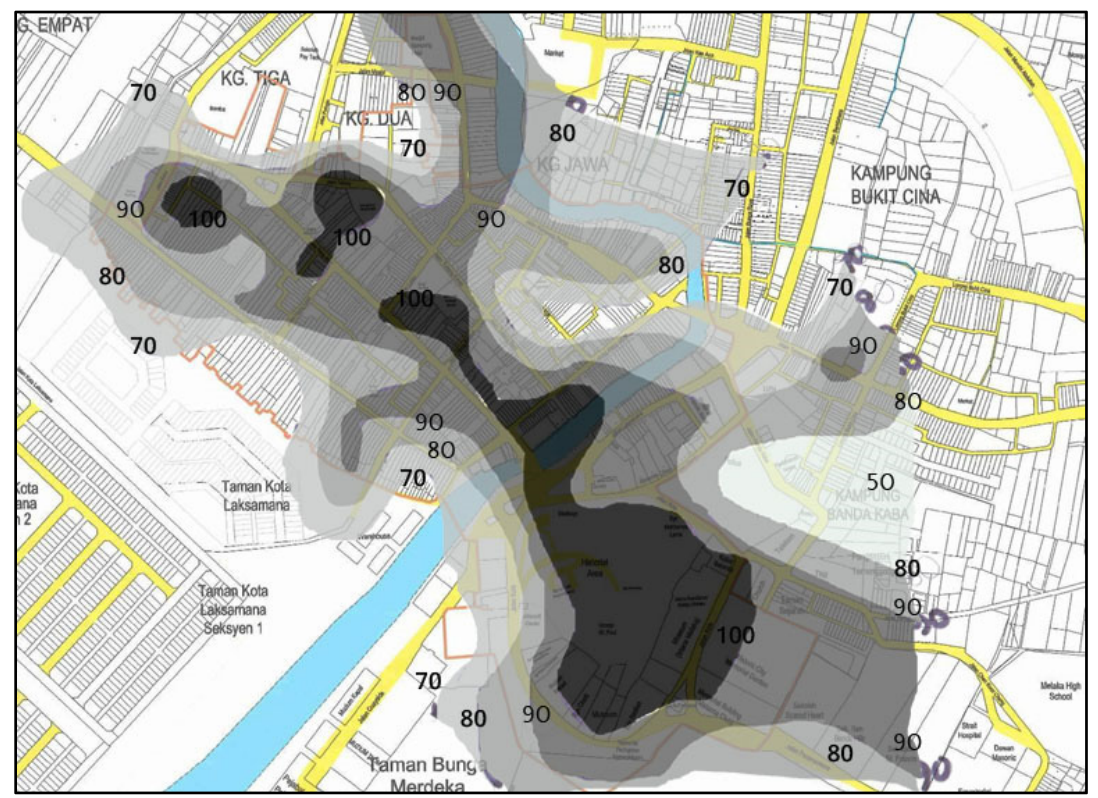

Figure 2: Iso-lines map representing the quality of townscape assessed in 2013. 
This visual representation helps to indicate where the changes have taken place and areas that needs more improvement on the townscape condition. However, to ascertain the reliability of the method, statistical data on economic growth and social changes from relevant authorities are collected to support the findings. A thorough study on environmental condition of the area is also needed.

\section{Conclusion}

The first round of townscape survey in 2010 acts as baseline indicator for the condition of the townscape of the studies area. It also highlighted areas that require further improvement, hence to support future regeneration initiatives. Meanwhile, the survey in 2013 indicates the changes that took place in the area. Measuring physical changes in urban regeneration scheme is important to track changes in the assessed area and is a part of urban morphology.

Physical changes of an area represent the amount of work that has been carried out in the area. By tracking its change, recorded evidence- in the form of quantitative measurement- could be made to ensure that necessary development for regeneration of the area was carried out as planned. The longitudinal study helps to record the impact of the development plan of the area in a periodical report. Thus, this could also provide evidence for urban morphology of the place in order to understand the spatial structure and character of a metropolitan area, city, town or village by examining the patterns of its component parts and the process of its development.

\section{Acknowledgements}

The authors would like to thank the Department of Higher Education, Ministry of Education Malaysia for the research grant. This research is carried out under Research Acculturation Grant Scheme (RAGS).

\section{References}

[1] Shipley, R. et al. (2004). Townscape Heritage Initiatives Evaluation: methodology for assessing the effectiveness of Heritage Lottery Fund projects in the United Kingdom. Environment and Planning C: Government and Policy 22 (4), pp. 523-542.

[2] Reeve, A., Goodey, B. and Shipley, R. (2007). Townscape assessment: the development of practical tool for monitoring and assessing visual quality in the built environment. Urban Morphology 11 (1), pp. 25-41.

[3] UNESCO (2010). Melaka and George Town, Historic Cities of the Straits of Malacca. UNESCO.org.

[4] Solomon, R. J. (1966). Procedures in Townscape Analysis. Annals of the Association of American Geographers 56 (2), pp. 254-268.

[5] Cooper J, Su M-1, Oskrochi R, 2013, The influence of fractal dimension and vegetation on the perceptions of streetscape quality in Taipei: with 
comparative comments made in relation to two British case studies. Environment and Planning B: Planning and Design 40(1) 43-62.

[6] Reeve, A., Shipley, R. and Goodey, B. (2008). Townscape evaluation: developing non aesthetic criteria to monitor change in historic urban settings. Journal of Urban Morphology 11 (1), pp. 25-41.

[7] Wong, C. (2006). Indicators for Urban and Regional Planning: The interplay of policy and methods. London Routledge, Taylor \& Francis Group.

[8] INHERIT (2007). Investing in Heritage. A Guide to Successful Urban Regeneration. European Association of Historic Towns and Regions.

[9] Miller, D. C. (1991). Handbook of Research Design and Social Measurement. 5th ed. California: SAGE.

[10] Sommer, B. and Sommer, R. (1997). A Practical Guide to Behavioural Research. Oxford: OUP.

[11] Walliman, N. (2006). Social Research Methods. London: SAGE.

[12] Said, S.Y (2010) Baseline methods of assessment for heritage-led regeneration: Melaka and George Town. Oxford Brookes University. Unpublished $\mathrm{PhD}$ thesis. 